\title{
¿ES EL ABORTO UN DERECHO EN EUROPA? COMENTARIO DE LA SENTENCIA "A, B y C v. IRLANDA", DEL TRIBUNAL EUROPEO DE DERECHOS HUMANOS
}

\author{
DR. FERNANDO REY MARTÍNEZ ${ }^{1}$
}

\begin{abstract}
RESUMO: A Corte Europeia de Direitos Humanos decidiu de maneira correta o caso "A, B e C v. Irlanda", apesar de problemas na argumentação relacionados, entre outras coisas, ao argumento que diferencia o status de proteção da gestante e do feto pelos direitos fundamentais. São traçadas considerações sobre o futuro da jurisprudência da Corte nessa área.

PALAVRAS-CHAVE: Aborto; Direitos Fundamentais; Corte Europeia de Direitos Humanos.

ABSTRACT: The European Court of Human Rights ruled correctly in the "A, B and C v. Ireland" case, despite problems in the reasoning adopted which relate, among other issues, to the argument that distinguishes the protective status enjoyed by the woman and the fetus in light of fundamental rights. Some remarks are made on the Court's possible future jurisprudence in this field. KEYWORDS: Abortion; Fundamental Rights; European Court of Human Rights.
\end{abstract}

SUMÁRIO: I. O Conflito; II. A Sentença; III. Comentário Crítico; Conclusões.

SUMMARY: I. The Conflict; II. The Ruling; III. Critical Commentary; Conclusions.

\section{EL CONFLICTO}

En el caso $A$, $B$ y $C$ v. Irlanda, de 16 de diciembre de 2010, el Tribunal Europeo de Derechos Humanos (en adelante, TEDH) se enfrenta directamente, por primera vez, a la cuestión de la interrupción voluntaria del embarazo en Europa, a partir del examen de la restrictiva regulación del aborto prevista en el ordenamiento irlandés. Se trata de una decisión de gran importancia, como cabe imaginar, que resuelve un asunto de los denominados de litigación estratégica (con tres casos dramáticos y con participación en el procedimiento de todo tipo de entidades a favor y en contra de la regulación irlandesa), altamente publicitado (incluso con audiencia pública ante el propio Tribunal),

Artigo recebido em 20.06.2011. Artigo aceito para publicação em 05.09.2011 mediante convite. ${ }^{1}$ Professor da Faculdade de Direito da Universidade de Valladolid, Espanha. rey@der.uva.es. 
y que marca la tendencia en este asunto, pero lo hace de manera particularmente controvertida, como lo demuestra que fuera aprobada por la Gran Sala tan "sólo" por once votos contra seis. Por ello no estoy seguro de que su doctrina, por otro lado, bastante ligada a las peculiaridades del sistema irlandés, esté llamada a perdurar por mucho tiempo.

Simplificando las cosas, de manera introductoria, podemos plantearnos si esta Sentencia es, a la luz del Convenio de Roma, una decisión simpática hacia una interpretación favorable del aborto (pro choice) o, por el contrario, antipática o sospechosa (pro life). Ciertamente, la decisión otorga finalmente amparo judicial a una de las tres demandantes, pero ello no autoriza a pensar que se trate de una decisión pro choice. Al contrario, estamos en presencia de una Sentencia que, con toda claridad, adopta un enfoque pro life. El Tribunal de Estrasburgo ha tenido abierta de par en par la oportunidad de declarar contraria al Convenio de Roma la prohibición del aborto en Irlanda, por excesivamente rigorista, es decir, por insuficiente protección de otros bienes de rango constitucional, como la salud de la mujer embarazada, pero deliberadamente no lo ha hecho.

En Europa, salvo el caso de la prohibición absoluta o cuasi-absoluta de la vida humana en formación frente al aborto que se da en tres microestados: Andorra, Malta y San Marino, entre los Estados grandes, sólo en Irlanda (con permiso de Polonia) se dispensa un régimen tan restrictivo del aborto. De ahí la relevancia de esta Sentencia en orden a determinar el estándar europeo de protección de la vida humana en formación y, simétricamente, los derechos de la mujer embarazada a abortar. Pues bien, una primera conclusión se impone: a juicio del Tribunal de Estrasburgo, hoy por hoy, y a diferencia de lo que ocurre con algunas regulaciones estatales, el aborto no es un derecho fundamental de las mujeres embarazadas que deba prevalecer normalmente frente a la protección de la vida humana en formación (al menos durante las primeras semanas de existencia) En cierto sentido, la Sentencia en examen es sobre todo interesante no tanto por lo que dice, sino por lo que se resiste a decir.

No obstante, por otro lado hay que tener en cuenta algunos otros elementos de la jurisprudencia de la Corte que sí podrían en el futuro permitir la interpretación del aborto voluntario como un derecho de las mujeres embarazadas. En el momento presente, a diferencia de la tradicional aproximación a este tema del ordenamiento norteamericano, a través de la potente noción de privacy, la Corte sostiene que no existe ese derecho a abortar en la penumbra del derecho al respeto a la vida privada (art. $8 \mathrm{CR}$ ), pero, al mismo tiempo, también afirma que las limitaciones estatales al aborto voluntario sí pueden llegar a violar tal derecho (que incluye "la integridad física y psicológica", en este caso de la mujer embarazada), sobre todo en el caso en el que, una vez establecida una determinada regulación estatal del aborto, no se adoptan, sin embargo, medidas efectivas para hacer practicable la posibilidad de abortar válidamente. Tal protección de la dimensión, 
por llamarla así, "procedimental" del aborto (una vez que éste ya fuera permitido bajo ciertas condiciones en la correspondiente legislación estatal) está firmemente establecida en la jurisprudencia de la Corte desde la sentencia Tysiac v. Polonia, de 20 de marzo de 2007, pasando por la protección que a la demandante "C" del caso que estamos examinado en $A$, B y C contra Irlanda, y llegando a la Sentencia R.R. contra Polonia, de 26 de mayo de 2011. Aunque la Corte no ha llegado a decir todavía que el aborto es un derecho que se ubica en la penumbra del respeto a la vida privada (art. 8), está cerca de decirlo, sobre todo si tenemos en cuenta la vis expansiva de tal derecho como fuente de creación de nuevos derechos y de nuevas dimensiones de otros ya reconocidos. Además, aunque la doctrina actual del Tribunal es la del fair balance, el equilibrio adecuado entre la protección del embrión o feto, de un lado, y el respeto a la vida privada de la mujer embarazada, de otro, lo cierto es que se ha negado a considerar que el embrión o feto sea titular del derecho a la protección de la vida del art. 2 del Convenio (aunque su vida sí sea protegible -una construcción muy semejante a la de la Sentencia del Tribunal Constitucional español 53/1985), mientras que la decisión de la mujer embarazada sí está, al menos parcialmente, protegida por un derecho del Convenio, el del respeto a su vida privada (art. 8). De modo que estamos en presencia de un equilibrio de entrada ya bastante desequilibrado entre las dos posiciones.

Adelanto también mi interpretación de la decisión en el caso contra Irlanda. Me parece que el Tribunal debería haber amparado a todas las demandantes porque resulta contrario al sistema del Convenio de Roma que el ordenamiento irlandés no prevea la licitud del aborto en el supuesto de grave riesgo para la salud física o psíquica de las mujeres embarazadas (cuya tutela se deriva también del Convenio). La argumentación del Tribunal ofrece algunos puntos débiles, bien observados por el voto discrepante, de los que daré cuenta más adelante, pero tampoco me resulta del todo convincente la argumentación de este último. Para poder demostrar las razones que me llevan a alcanzar esta conclusión, es preciso reconstruir, aunque sea brevemente, los principales pasos argumentativos de la Sentencia. Iré rápidamente a los puntos que considero decisivos.

\section{LA SENTENCIA}

La argumentación del Tribunal se estructura en las siguientes ideas.

$1^{\text {a) }}$ El derecho a la vida privada (art. $8 \mathrm{CR}$ ) no confiere el derecho a abortar (párrafo 214), pero la regulación estatal sobre interrupción del embarazo puede limitar ese derecho. Ahora bien, la terminación del embarazo es una decisión que no pertenece sólo a la vida privada de la mujer, porque está íntimamente conectada con el feto en desarrollo. De ahí que "el respeto al derecho de la vida privada de la mujer debe ser balanceado con otros derechos en conflicto, incluyendo los del niño no nacido" (p. 213) A partir de este planteamiento general, la Sentencia distingue los casos de A y B, de un lado, y el de C, de otro. Las tres demandantes, A, B y C, residían en Irlanda 
(A y B eran irlandesas, C lituana), pero fueron a Reino Unido para abortar. La diferencia entre las dos primeras y la última es que la situación de ésta podía entenderse incluida en la única excepción que el ordenamiento irlandés prevé de prohibición del aborto, la del riesgo para la vida de la madre (ya que estaba enferma de cáncer), lo que no ocurría en el caso de A ni de $B$ (por más que su situación personal fuera dramática: embarazo no deseado, carencia de recursos económicos, complicaciones de salud tras el parto, etc.) En consecuencia, la Sentencia pasa a distinguir el caso de A y B, por una parte, respecto del de $C$, por otra.

$\left.2^{a}\right)$ Caso de A y B, esto es, de abortos que no son permitidos por el ordenamiento irlandés. El Tribunal examina si la prohibición irlandesa del aborto por razones de salud o bienestar (y no sólo por peligro para la vida de la madre) vulnera el derecho al respeto de la vida privada de las demandantes. Para ello, la Sentencia emplea el habitual test o estándar de proporcionalidad de los límites de los derechos: si están de acuerdo con la ley, si persiguen un objetivo legítimo y sin son necesarios en una sociedad democrática.

a) ¿Está el límite previsto por la ley? El Tribunal observa que sí, y nada menos que por la propia Constitución (art. 40.3.3).

b) ¿Persigue una finalidad legítima? La Sentencia concluye afirmativamente: tal finalidad sería la protección de "profundos valores morales" de la sociedad irlandesa relativas a la naturaleza de la vida humana, que se reflejan en la aprobación por la mayoría del pueblo irlandés de la cláusula constitucional contra el aborto (art. 40.3) durante el referéndum de 1983.

c) ¿Se trata de un límite necesario en una sociedad democrática? El Tribunal también concluye positivamente. En este punto, la cuestión crucial es la del grado de apertura del margen de apreciación de los Estados, que será mayor allí donde no exista un consenso europeo relevante sobre un asunto determinado. La Sentencia observa que sí existe un consenso europeo en orden a permitir el aborto de modo más amplio que en Irlanda, pero, trayendo el precedente de Vo v. Francia, de 8 de julio de 2004, sostiene que no existe ese consenso europeo sobre cuándo comienza la vida humana, y, por consiguiente, el margen de apreciación estatal sobre el aborto es máximo. El Tribunal concluye, pues, que la regulación irlandesa que prohíbe el aborto por razones de salud o bienestar de la mujer no viola el derecho a su vida privada del Convenio, sobre todo si se tiene en cuenta que la propia Constitución irlandesa (art. 40.3.3) permite salir del país a abortar y establece, además, el deber de informar sobre esta posibilidad.

$3^{a}$ ) Caso de C, esto es, de un aborto que sí podría ser válido en Irlanda porque estaba en peligro la vida de la madre (enferma de cáncer). Aquí la cuestión es que, a pesar de que la demandante se encontraba prima facie en una situación de aborto válido conforme al ordenamiento irlandés, éste no había desarrollado la previsión constitucional de licitud del aborto en el 
supuesto del peligro para la vida de la madre, de modo que carecía de procedimiento accesible y efectivo para ello. El Tribunal sí estima en este supuesto que se ha violado el derecho al respeto a la vida privada de la demandante y le concede, además, una indemnización de quince mil euros por daños no patrimoniales. El caso de C remite a la misma línea jurisprudencial de los asuntos Tysiac contra Polonia, de 20 de marzo de 2007 y R.R. v. Polonia, de 26 de mayo de 2011. En todos estos casos, la Corte condenará a los Estados por haber previsto en sus legislaciones, aunque fuera de modo muy restrictivo, la posibilidad de realizar abortos válidos cuando peligra la vida de la mujer embarazada (Tysiac contra Polonia y C contra Irlanda) o cuando el feto esté en peligro de sufrir daños ireversibles y graves (R.R. contra Polonia), y, sin embargo, no haber establecido medidas para hacer efectiva en la práctica esa posibilidad. En R.R. contra Polonia, por ejemplo, la demandante, a la que se había diagnosticado una sospecha de grave malformación de su feto, no tuvo acceso a la prueba de amniocentesis para confirmar ese diagnóstico durante el periodo de tiempo en el que el ordenamiento polaco permite el aborto por esa situación, de modo que finalmente no pudo abortar y su hijo nació con una malformación grave, el síndrome de Turner. En este caso, la Corte no sólo apreció vulneración del derecho al respeto a su vida privada (art. 8), sino que ha llegado a estimar, incluso, la presencia de un trato degradante prohibido por el Convenio de Roma en su artículo tercero.

\section{COMENTARIO CRÍTICO}

El caso de C está correctamente decidido, dentro de una línea jurisprudencial firmemente establecida, y, en mi opinión, no plantea mayores problemas interpretativos. El punctum ardens se sitúa en relación con la decisión sobre A y B. En este punto, la argumentación del Tribunal es manifiestamente discutible. Señalaré los aspectos que me parecen más problemáticos.

(10) En primer lugar, la propia metodología que utiliza el Tribunal, que no considero técnicamente depurada. En efecto, la Sentencia parece plantear el asunto como la valoración de si existe en el ordenamiento irlandés un "balance justo" entre el derecho al respeto a la vida privada de la mujer (art. $8 \mathrm{CR}$ ) y la protección de la vida humana en formación, esto es, como una ponderación entre derechos fundamentales, pero, al mismo tiempo, sigue negándose a considerar al no-nacido como "persona" a proteger por el derecho al respeto a la vida del art. 2 del Convenio. Evidentemente, trata al feto, en la decisión del caso, como persona, pero, trayendo la doctrina Vo contra Francia, se obstina en negarle teóricamente tal status.

Por otro lado, aunque la Sentencia anuncia como criterio de resolución del caso un supuesto de conflicto y ponderación de derechos, en realidad, la metodología que emplea no es la del conflicto entre derechos, sino la del juicio de proporcionalidad, es decir, la del examen de si está o no justificado el límite (la prohibición del aborto por razones de salud o bienestar de la mujer) 
de un derecho fundamental (el derecho a la vida privada de la mujer del art. $8 \mathrm{CR}$ ) Y, por tanto, no estamos en un supuesto de ponderación entre dos derechos de igual rango (vida privada de la mujer/protección de la vida del feto), sino de valoración de un límite (restricción para abortar) impuesto a un único derecho (vida privada de la mujer).

$\left(2^{\circ}\right)$ Se podría debatir también sobre la finalidad legítima perseguida por la legislación irlandesa. Se trata de un asunto crucial. El Tribunal apela a profundos valores morales de la sociedad irlandesa sobre la cuestión del aborto. Pero la cuestión dista de estar clara. La regulación irlandesa es verdaderamente curiosa. Se puede calificar, además, de esquizofrénica porque el art. 40.3 de la Constitución, al mismo tiempo que prohíbe el aborto salvo que esté en peligro la vida de la madre, incluye un derecho fundamental verdaderamente original, una suerte de derecho al turismo abortivo en otro país, estableciendo el derecho de las embarazadas a viajar (válidamente) a otro país para abortar y a ser debidamente informadas de cómo hacerlo. Que exista esta posibilidad constitucional fue, como se ha señalado (p. 241), realmente decisivo para que el Tribunal de Estrasburgo considerara que el ordenamiento irlandés era conforme al art. 8 del Convenio. La Sentencia llega a comentar (p. 239) que la regulación irlandesa pudiera ser considerada "ineficaz para proteger al no-nacido" (en la medida en que "un número substancial de mujeres toman la opción abierta para ellas de abortar fuera del país"), pero no concluye a partir de aquí que, quizá, los "profundos valores morales" no fueran tan "profundos" porque lo que se niega en Irlanda se permite (e incluso podría entenderse que constitucionalmente se fomenta) fuera del país. La opción del constituyente no es tanto en contra del aborto, sino del aborto en suelo irlandés. Los "profundos valores morales" son de corto alcance: su extensión sólo llega hasta las fronteras del Estado.

$\left(^{\circ}\right)$ Pero el verdadero punto de fractura de la argumentación de la Sentencia, como correctamente pone de relieve el voto particular de los seis magistrados discrepantes, se halla en la afirmación de que no existe consenso europeo en materia de aborto y por ello el margen de apreciación estatal es amplio, de modo que una regulación restrictiva como la irlandesa sería válida. La Sentencia, en contra de lo esgrimido por el Gobierno irlandés, sí identifica un consenso europeo sobre la validez del aborto por razones de salud o bienestar de la mujer, frente a la restrictiva regulación irlandesa, que permite sólo el aborto por peligro para la vida de la madre, pero, después de sostener esto, un tanto sorprendentemente, trae el precedente de Vo contra Francia, y razona que lo verdaderamente decisivo es que no existe en Europa consenso sobre cuándo comienza la vida humana y, por tanto, que los Estados disponen de un amplio margen de apreciación para regular el aborto. That's the point. El Tribunal se niega expresamente a emplear un criterio interpretativo evolutivo y a considerar, en consecuencia, que se deriva del art. 8 del Convenio la exigencia de que 
estatalmente se configure (aunque sea de modo más o menos restrictivo) la posibilidad de un aborto por razones de salud o de bienestar de la mujer embarazada.

La utilización de Vo contra Francia, de 8 de julio de 2004, como precedente de este caso resulta discutible porque se refería a otro asunto. En la Sentencia de 2004, la demandante, una ciudadana francesa llamada Thi-Nho Vo, alegaba que las autoridades judiciales nacionales habían violado el art. 2 del Convenio porque la conducta del médico que fue responsable de la muerte de su feto de seis meses in utero no se calificó como un homicidio intencional (el médico del Hospital General de Lyon cometió un error trágico pues confundió a la demandante con otra paciente llamada de modo semejante, Thi Thanh Van Vo, y, como consecuencia de su intervención, perforó el saco amniótico de la demandante, lo que produjo la muerte de su feto) La demanda sostenía que el término "toda persona" del art. 2 incluía a todo ser humano, también a los concebidos pero todavía no nacidos y, por tanto, las legislaciones de los Estados debían asegurar la protección de éstos tipificando penalmente el homicidio involuntario, incluso aunque, en ciertos casos, permitieran el aborto. El asunto en litigio era, pues, si la ausencia de una respuesta criminal dentro del sistema jurídico francés para castigar la destrucción involuntaria de un feto constituía un fallo estatal en la protección del derecho a la vida en el sentido del art. 2 del Convenio. El Tribunal recuerda, en primer lugar, las escasas decisiones anteriores, tanto suyas como, sobre todo, de la Comisión, concluyendo que el nasciturus no ha sido visto por ellos como una "persona" directamente protegida por el art. 2 del Convenio y que aunque el no-nacido tuviera un "derecho" a la "vida", estaría implícitamente limitado por los derechos de la madre, aunque tampoco se ha excluido la posibilidad de que en ciertas circunstancias se pueda extender la protección al niño no-nacido. Es preciso que exista un equilibrio entre los intereses de la madre y la necesidad de asegurar protección al no-nacido. El Tribunal justifica su interpretación en "el claro deseo de establecer un equilibrio... respecto de las dimensiones jurídicas, médicas, filosóficas, éticas y religiosas a la hora de definir qué sea un `ser humano' tomadas en cuenta por las distintas regulaciones del asunto en el ámbito de los Estados".

La cuestión de cuándo comienza el derecho a la vida debe remitirse, declara el Tribunal, al margen de apreciación de los Estados por dos razones: primera, porque esta cuestión (el estatuto jurídico del embrión y del feto) no ha sido ni siquiera resuelta por los propios Estados y segunda, porque no existe un "consenso europeo" sobre la definición científica y jurídica del comienzo de la vida, aunque están empezando a recibir embriones y fetos alguna protección a la luz de los progresos científicos y las potenciales consecuencias de la investigación en ingeniería genética, procreación asistida y experimentación con embriones. Como mucho, "podría decirse que es una idea compartida entre los Estados que el embrión 
y el feto pertenecen a la raza humana". "La potencialidad de estos seres y su capacidad para llegar a ser personas (lo que les asegura protección en diversos Estados desde el punto de vista del derecho civil), requiere protegerles en nombre de la dignidad humana, sin necesidad de convertirlos en una "persona" con "derecho a la vida" a los efectos del art. 2 CEDH". En cualquier caso, continúa razonando el Tribunal Europeo, "no es deseable, ni posible, responder en abstracto a la cuestión de si un no-nacido es una persona a los efectos del art. 2 CEDH". Y mucho menos en el caso en examen, porque, incluso asumiendo que ese precepto fuera aplicable, el Estado francés no ha fallado a la hora de cumplir los requerimientos procedimentales de protección inherentes en el art. 2 CEDH. La demandante entendía que sólo una sanción penal cumpliría tales requerimientos, pero el Tribunal no comparte este punto de vista para el caso de las negligencias médicas. La demandante disponía de una acción por daños ante los tribunales administrativos, que el Tribunal consideró como un "remedio efectivo" y, por tanto, incluso asumiendo que el art. 2 CEDH fuera aplicable en este caso, falló que no había habido violación de tal precepto.

Pues bien, resulta evidente la influencia de la doctrina Vo contra Francia en la Sentencia A, B y C contra Irlanda, pero también la manifiesta diferencia de los casos planteados en ambas decisiones. La cuestión no era en la última Sentencia determinar cuándo comienza la vida humana a la hora de precisar los deberes de protección por parte del Estado, sino qué ocurre con el aborto por razones de salud y/o bienestar de la mujer embarazada en Europa y lo que ocurre es que en (casi) toda Europa (aunque se mantenga un significativo debate social) jurídicamente se permite. Sí existe ese consenso europeo, como la propia Sentencia de la mayoría advierte, aunque luego no extraiga de ello consecuencia alguna porque cambie, de modo interesado, este consenso por la falta de consenso sobre cuándo comienza la vida humana... Y puesto que existe consenso europeo en materia de protección de la salud y/o bienestar de las mujeres en relación con su decisión sobre interrumpir el embarazo, el TEDH podría haber considerado que, por efecto de una interpretación evolutiva del Convenio de Roma, el margen estatal de apreciación se habría visto reducido en este ámbito, de modo que una cosa sería que los Estados configuraran lícitamente conforme al Convenio de un modo más amplio o más restrictivo dicha posibilidad de abortar, pero otra muy distinta que un ordenamiento cualquiera no permitiera a las mujeres embarazadas abortar de ningún modo en este supuesto (como hace la regulación irlandesa), en cuyo caso la compatibilidad con el Convenio resultaría más que dudosa.

\section{CONCLUSIONES}

Así pues, en A, B y C contra Irlanda, el Tribunal Europeo ha tendido algunas trampas argumentales, bien observadas por el voto particular de los seis magistrados discrepantes. También es interesante retener de dicho voto particular que, a la hora de valorar si la regulación irlandesa trazaba un 
equilibrio apropiado entre el derecho al respeto de la vida privada de la mujer embarazada y la protección del feto, no se tuvo en cuenta algunos otros aspectos relevantes, como el considerable coste económico y de otro tipo que supone para las mujeres que residen en Irlanda tener que viajar al extranjero para abortar (manifestadas precisamente en los casos que motivaron el conflicto: A tenía en el momento de abortar cuatro hijos pequeños, uno de ellos discapacitado, era alcohólica y madre soltera; B tuvo que pedir la tarjeta de crédito de un amigo para pagarse el viaje a Inglaterra) y, sobre todo, las arcaicas y graves sanciones que todavía ahora se imponen en Irlanda por abortar. Sin embargo, no comparto el poderoso alegato abortista o pro choice que abre dicho voto particular y que creo que no es en absoluto necesario en relación con las atinadas afirmaciones que se vierten en él más tarde criticando la argumentación de la mayoría de la Gran Sala. En efecto, el párrafo segundo del voto sostiene que los valores protegidos (el derecho del feto y el de "una persona viva" -se refiere a la mujer embarazada, claro, pero se olvida que el feto también es un ser vivo) "son, por naturaleza, distintos: de un lado, están los derechos de una persona que ya participa, de una manera activa, en las relaciones sociales; de otra, los derechos del feto dentro del cuerpo de la madre, cuya vida no ha sido definitivamente determinada en la medida en que no se ha completado el proceso que conduce a su nacimiento y cuya participación en la vida social aún no ha comenzado". Esta argumentación me parece fuertemente criticable porque conduce a una insoportable jerarquización de situaciones vitales humanas, en función, además, de un criterio discutible, la participación en las relaciones sociales, que llevaría también a considerar el menor valor de la vida de personas especialmente vulnerables y con dificultades de comunicación, como el de los enfermos, el de los menores, el de las personas aisladas, etc. Una visión antropológica subyacente de este tipo es enormemente peligrosa e inquietante. Claramente apunta a una visión del aborto como derecho incondicional de la mujer embarazada, que debe prevalecer siempre sobre la protección de la vida humana en formación, de menor valor social.

En mi opinión, el Tribunal Europeo no ha resuelto correctamente A, B y C contra Irlanda, porque debería haber fallado que una regulación estatal que no contemple la salud y/o bienestar de la mujer embarazada como causa válida de aborto es contraria al art. 8 del Convenio de Roma (otra cosa es que lo haga de modo más o menos restrictivo, que éste sí es asunto que se debería dejar al libre margen de apreciación estatal), pero, por fortuna, me parece adecuado que siga sosteniendo que, en la regulación del aborto, los Estados europeos deben también considerar la protección efectiva de la vida humana en formación. Incluso, con esta doctrina del "balance apropiado" en la mano, podría haber dudas sobre si aquellos ordenamientos estatales, como el español, que configuran el aborto voluntario como un derecho de la mujer embazada, al menos durante las 
primeras semanas de existencia del feto, es compatible o no con el deber de respeto a la vida humana en formación que se deriva del Convenio de Roma según el Tribunal Europeo de Derechos Humanos. Posiblemente, la doctrina del margen estatal de apreciación sería llamada de nuevo en causa para evitar una declaración de incompatibilidad, pero no dejaría de resultar curioso que una misma regulación europea permita la prohibición penal cuasi-absoluta del aborto al mismo tiempo que su consideración como derecho fundamental de las mujeres embarazadas. Una misma conducta puede ser un tipo penal y un derecho fundamental. Para el Tribunal de Estrasburgo será difícil (y quizá no fuera tampoco deseable) abandonar en el futuro su actual postura de funambulista y pasar a sostener un discurso más fuerte sobre el problema constitucional del aborto en Europa. Su doctrina actual remite a la regulación estatal porque se niega a dar primacía absoluta a la protección de la vida del embrión o feto, pero también a considerar que el aborto sea, sin más, un derecho más del respeto a la vida privada de las mujeres embarazadas. De momento, se limita a invalidar aquellas situaciones incoherentes en las que un Estado permite el aborto bajo ciertas condiciones (en un contexto restrictivo: Polonia e Irlanda), pero luego lo impide en la práctica porque no pone los medios para ello. Esta protección procedimental, a partir de las garantías positivas que se derivan del art. 8 del Convenio, me parece inobjetable. ¿Irá el Tribunal más allá en el futuro? En A, B y C contra Irlanda se ha negado claramente a ir más allá, en un caso que quizá lo requería sin desarbolar por completo la doctrina (que me parece también razonable) del fair balance, del justo equilibrio entre la protección de la vida del embrión o feto y la decisión de la mujer embarazada. 